\title{
Impact of coronavirus pandemic crisis in endoscopic clinical practice: Results from a national survey in Brazil
}

\section{(ㄷ)(1) $\ominus$}

Authors

Vitor Nunes Arantes ${ }^{1,2}$, Bruno Costa Martins ${ }^{3}$, Raphael Seqatto ${ }^{4}$, Daniela Medeiros Milhomen-Cardoso ${ }^{5}$, Tomazo Prince Franzini ${ }^{6}$, Anna Maria Zuccaro ${ }^{7}$, Jairo Silva Alves ${ }^{4}$, Fauze Maluf-Filho ${ }^{8}$

Institutions

1 Faculdade de Medicina da Universidade Federal de Minas Gerais - Alfa Institute of Gastroenterology, Minas Gerais, Brazil

2 Hospital Mater Dei Contorno - Endoscopy, Minas Gerais, Brazil

3 São Paulo University Medical School - Endocopy Unit, São Paulo, Brazil

4 Federal University of Minas Gerais - Endoscopy, Belo Horizonte, Brazil

5 Goiania General Hospital - Endoscopy, Goiania, Brazil

6 Hospital das Clinicas from University of Sao Paulo School of Medicine - Department of Gastroenterology, São Paulo, Brazil

7 Hospital Federal de Ipanema - Endoscopy, Rio de Janeiro, Brazil

8 University of São Paulo - Department of Gastrointestinal Endoscopy, São Paulo, Brazil

submitted 12.5 .2020

accepted after revision $\quad 19.5 .2020$

Bibliography

DOI https://doi.org/10.1055/a-1183-3324 |

Endoscopy International Open 2020; 08: E822-E829

(c) Georg Thieme Verlag KG Stuttgart · New York elSSN 2196-9736

Corresponding author

Vitor Nunes Arantes, Faculdade de Medicina da

Universidade Federal de Minas Gerais - Alfa Institute of Gastroenterology, Av. Prof. Alfredo Balena 110, 2o andar, Dept. Cirurgia, Belo Horizonte Belo Horizonte, Minas Gerais 30130100, Brazil

Fax: + 553125107764

arantesvitor@hotmail.com
ABSTRACT

Background and study aims In March 2020, the World Health Organization declared coronavirus disease of 2019 (COVID-19) as a pandemic, mobilizing all countries to contain the disease spread. Activity in endoscopy centers globally was severely affected. We conducted a national survey aiming to assess the impact of the COVID-19 outbreak on endoscopic clinical practice in Brazil.

Methods In April 2020, 3,719 associate members of SOBED (Brazilian Society of Digestive Endoscopy) were invited to respond to an electronic survey. An Internet link was established to provide access to the online questionnaire with 40 questions regarding personal profile, endoscopy unit logistics and schedule, availability and use of personal protective equipment (PPE), financial impact, and exposure to COVID-19.

Results A total of 2,131 individuals (67\%) accessed the questionnaire and 1155 responses were received. After review, 980 responses were considered valid. According to almost $90 \%$ of respondents, endoscopy activity was restricted to urgent procedures, in both public and private hospitals. All respondents increased PPE use after the outbreak, however, institutions provided adequate PPE to only 278 responders (28.7\%). Significant income loss was universally reported. A total of 10 practitioners ( $1 \%$ ) reported COVID19 infection and attributed the contamination to endoscopic procedures.

Conclusions Based on this nationwide survey with almost 1,000 respondents, the COVID-19 pandemic substantially reduced the activity of endoscopy units in private and public settings. The pandemic increased awareness of PPE use, but its availability was not universal and $1 \%$ of the respondents became infected with COVID-19, allegedly due to exposure during endoscopic procedures.

\section{Introduction}

The severe acute respiratory syndrome coronavirus 2 (SARSCoV-2) outbreak began in December 2019 in China and the infection was rapidly disseminated all over the globe [1]. Only 3 months later, the World Health Organization (WHO) declared the infection as a pandemic, mobilizing all countries to contain the advance of the disease [2]

Endoscopy is associated with production of secretions, splash and droplets, besides the risk of a patient coughing and 
sneezing. Thus, theoretically there is a risk of virus transmission due to aerosol dissipation contamination of healthcare personnel (HCP) involved with endoscopy procedures. Although endoscopy units are not directly involved with emergency treatment of patients with the new coronavirus disease of 2019 (COVID-19), their operations were severely affected in many countries hit by the outbreak. Moreover, many infected patients present mild or no symptoms, facilitating virus spread among undocumented carriers [3-6]. The main mechanism of SARS-CoV-2 infection is through direct contact with infected droplets, but there is also a possibility of airborne transmission during aerosol-generating procedures [7]. To mitigate this risk, WHO recommends use of respirator masks (N95/PFF2) by those involved with clinical management of patients who test positive for COVID-19 or are suspected of having it [7].

Currently, there is intense debate concerning behavioral precautions and the proper use of personal protective equipment (PPE), particularly for medical interventions that produce aerosol, such as endotracheal intubation, bronchoscopy, and upper endoscopy. Multiple endoscopy societies have issued position statements and guidelines with safe practice recommendations for endoscopic procedures during the COVID-19 outbreak [8-15]. Although some variations are noticeable among the different guidelines, the core aspects include: postponement of elective procedures; triage of patients and screening for respiratory symptoms or fever; rearrangement of exam schedule, staffing, and waiting areas; and supply of appropriate PPE for endoscopy procedures, including hairnets, respirator masks, gowns, goggles/face shields. Furthermore, for patients with suspected of having or confirmed to have COVID-19, some authors recommend carrying out endoscopic procedures in negative-pressure rooms [14].

The sudden need for all these requirements and adjustments in infrastructure and endoscopy waiting lists has challenged endoscopy centers worldwide, particularly given the PPE shortage in countries severely affected by the pandemic. Likewise, under certain circumstances, all elective procedures had to be suspended or postponed, and only urgent interventions were maintained. Although essential to the control of the pandemic, these initial measures have generated not only fear and anxiety among endoscopy providers, but they have also had a significant economic impact. In addition, there is increasing concern about the future and conditions that may be required to minimally return to endoscopy standard practice.

Considering the different realities of economical resources, medical resources, and disease prevalence in a country with continental dimensions, we conducted a national survey to assess the impact of the COVID-19 outbreak among Brazilian endoscopy centers and practitioners. This electronic survey was created by the Scientific Commission of the Brazilian Society of Digestive Endoscopy (SOBED), with the aim of analyzing the burden of the COVID-19 pandemic on endoscopy activity on the largest endoscopy association in Latin America.

\section{Methods}

In April 2020, 3,719 endoscopist members of SOBED included in our association's mailing list were invited to respond to a national electronic survey, created by the SOBED Scientific Commission. An Internet link was established to provide access to the online questionnaire using Survey Monkey software. The questionnaire included 40 questions regarding personal profile, impact of the pandemic on logistics and routines in endoscopy units, availability and use of PPE, financial impact, and exposure of endoscopists to COVID-19.

The study was conducted according to Helsinki Declaration and the Ethics Committee and the Directory Advisory Board of SOBED approved the survey. Informed consent was required from all individuals who submitted responses to the study. All endoscopists were encouraged to provide responses to the survey that reflected, as closely as possible, the reality in their clinical practices. The investigators reviewed all responses and considered them valid if more than $30 \%$ of the questions were addressed.

Prior to national enrollment, a pilot questionnaire was distributed to the members of the SOBED Scientific Committee to complete and provide feedback. That enabled the investigators to test the software and refine the questionnaire before of sending it to all Society members. The questionnaire was sent on three separate dates from April 9 to April 17, 2020, however, the link permitted only a single response per individual. During this 2-week period, the number of confirmed cases of COVID19 in Brazil increased from 20,000 to 40,000. In addition, to increase the response rate, advertising messages were sent via all digital media platforms of SOBED inviting practitioners to access the online survey.

Data were collected and extracted with graphs and tables from the software database and prepared for statistical analysis, which was basically descriptive given the characteristics of the survey. Variables were summarized using absolute and relative frequencies, weighted means and medians. Percentages were calculated based on the total number of survey participants and the number of responses to each individual question.

\section{Results}

A total of 2131 individuals (67\%) accessed the questionnaire and 1155 responses were received (36.3\% of total number of invited endoscopists). After the review, 175 responses (15\%) were excluded (12 individuals denied consent and 163 sent incomplete responses). Thus, 980 responses (85\%) were considered valid and included in the study ( $\mathbf{F i g} \mathbf{1}$ ). Responses were received from 25 of 26 Federation States ( $\mathbf{F i g}$. 2 ). Among the respondents, 699 were male (71.3\%) and 281 female (28.7\%). In Brazil, physicians typically work in more than one institution. The majority of respondents stated that they work in private practice, either in ambulatory endoscopy centers (710 physicians, $73.3 \%$ ) or private hospitals ( 579 physicians, $59.7 \%$ ). $>$ Table 1 lists respondent profiles, age distribution, and years of endoscopy practice. 


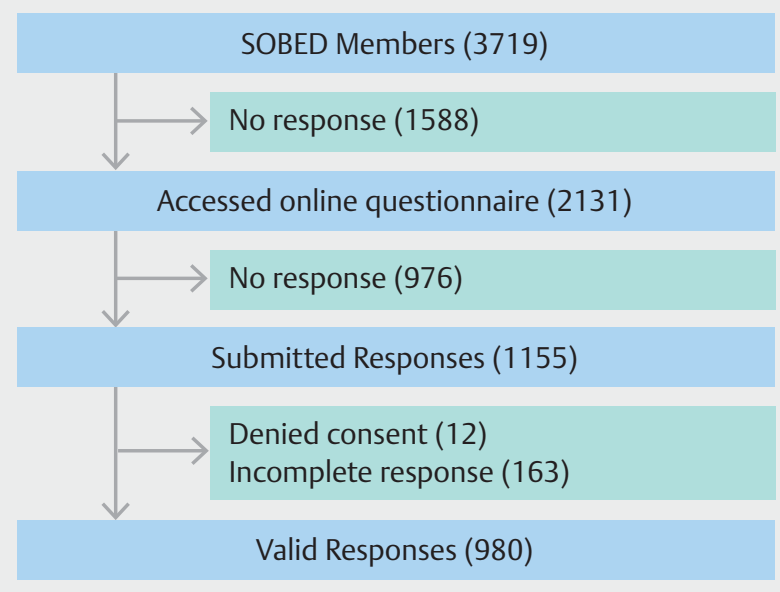

- Fig. 1 Workflow of the study.

\section{Impact on endoscopy unit logistics and exam schedule}

Since the COVID-19 outbreak reached Brazil in the beginning of March 2020, it has a major impact on endoscopy clinical practice. Notably, in $85.9 \%$ of private hospitals and $89.6 \%$ of public hospitals, only urgent procedures or exams that could not be postponed have been performed so far. Of ambulatory (outpatient) centers, $65.7 \%$ had their activities entirely suspended and $33.2 \%$ were still open although they were performing fewer procedures ( $\mathbf{F i g . 3}$ ). For 857 respondents ( $87 \%$ ) endoscopy procedures were interrupted indefinitely for 2 to 4 weeks, and only 50 participants ( $5 \%$ ) maintained an unchanged number of procedures.

Regarding patient willingness to undergo endoscopic procedures, the absolute majority of respondents (93.5\%) stated that patients were willing to postpone their procedure, whereas $6.5 \%$ of respondents stated that patients preferred to undergo their procedure anyway.

Almost all endoscopists (92.5\%) introduced triage for respiratory symptoms for patients referred for endoscopic procedures. Triage was performed at admission according to 533 respondents (76.4\%), whereas 411 respondents (58.9\%) preferred to contact patients by phone ahead of a procedure. Only five respondents $(0.72 \%)$ said they requested patients screening with polymerase chain reaction tests for COVID-19 prior to elective endoscopic procedures.

Endoscope disinfection procedures remained unchanged for 535 participants $(67.4 \%$ ), while 46 respondents $(5.8 \%)$ said sterilization time was increased. Approximately $40 \%$ of respondents altered their process for procedure room sanitation. Ac-

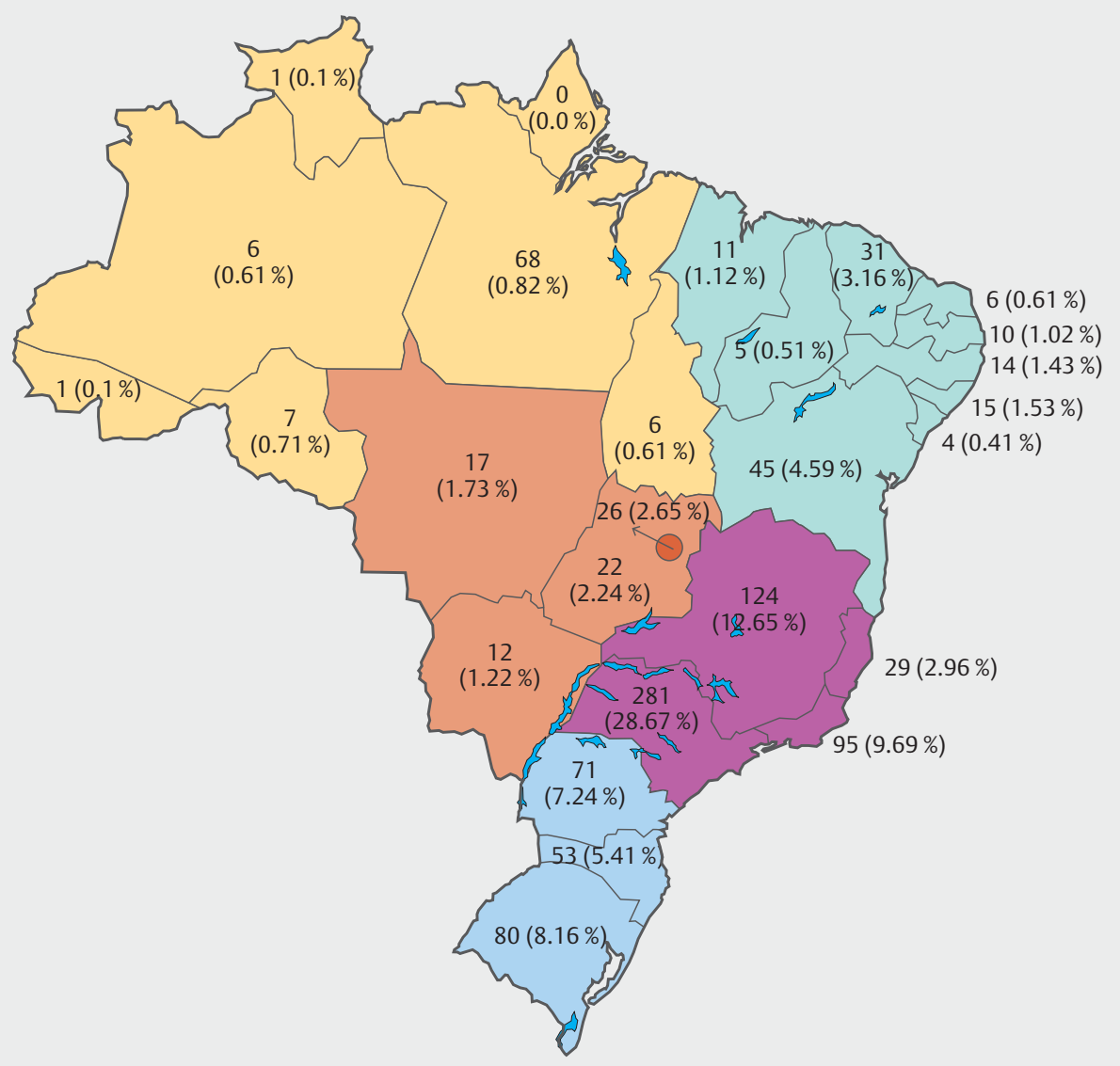

Fig. 2 Distribution of respondent endoscopists according to Brazil's regions and states. 
- Table 1 Characteristics of respondents.

\begin{tabular}{|c|c|c|}
\hline & $\mathbf{N}$ & $\%$ \\
\hline \multicolumn{3}{|l|}{ Sex } \\
\hline - Male & 699 & $71.3 \%$ \\
\hline - Female & 281 & $28.7 \%$ \\
\hline \multicolumn{3}{|l|}{ Age } \\
\hline - <30 years & 9 & $0.9 \%$ \\
\hline . $30-40$ years & 287 & $29.3 \%$ \\
\hline - 40-50 years & 297 & $30.3 \%$ \\
\hline . 50-60 years & 220 & $22.5 \%$ \\
\hline - >60 years & 167 & $17 \%$ \\
\hline \multicolumn{3}{|l|}{ Place of work } \\
\hline - Ambulatory center & 710 & $73.3 \%$ \\
\hline - Private hospital & 579 & $59.8 \%$ \\
\hline - Public hospital & 410 & $42.3 \%$ \\
\hline - University hospital & 193 & $19.9 \%$ \\
\hline \multicolumn{3}{|c|}{ Years of endoscopy practice } \\
\hline - <5 years & 100 & $10.2 \%$ \\
\hline - 5-10 years & 192 & $19.6 \%$ \\
\hline - 10-20 years & 276 & $28.2 \%$ \\
\hline - 20-30 years & 271 & $27.6 \%$ \\
\hline - >30 years & 141 & $14.4 \%$ \\
\hline
\end{tabular}

cording to 697 respondents (86.7\%), a negative pressure room was not available for endoscopic procedures. In contrast, 40 endoscopists used this room for all procedures (4.9\%) and 66 $(8.2 \%)$ used this room for patients suspected of having or confirmed to have COVID-19.

\section{Availability and use of PPE}

PPE use changed substantially comparing the phases before and during the COVID-19 pandemic, particularly regarding adoption of hairnets, goggles, face shields, N95 masks, and water-resistant gowns ( $\triangleright$ Fig. 4 ). The hospital/clinic provided adequate PPE according to only 278 of the respondents (28.7\%). As a result, 377 physicians (38.9\%) purchased their own PPE. At least 400 endoscopists (41.2\%) experienced difficulty in arranging for important PPE devices, such as N95 masks and face shields. It is of concern that 93 physicians (9.4\%) either did not have access to the institutional directory board or failed to convince them to provide proper PPE for endoscopy providers. As a result, 111 participants (11.3\%) canceled endoscopic procedures for lack of PPE and, most concerning, 214 endoscopists (21.8\%) stated that they performed endoscopic procedures without proper PPE.

Regarding the correct use and removal of PPE for COVID-19, $69.9 \%$ of endoscopists indicated that they learned their techniques from Internet videos and other online publications, $40 \%$ from their institution's protocol, $11.4 \%$ in collaboration with colleagues, and $5 \%$ said they were not using a systematic technique.

In terms of PPE usage and alteration of endoscopic procedure schedules, the following guidelines and recommendations were mainly followed by the respondents: SOBED (85.6\%), Health Minister of Brazil (39.9\%), hospital/clinic local guideline (31.2\%), World Health Organization (30\%), and international endoscopy societies (22.3\%).

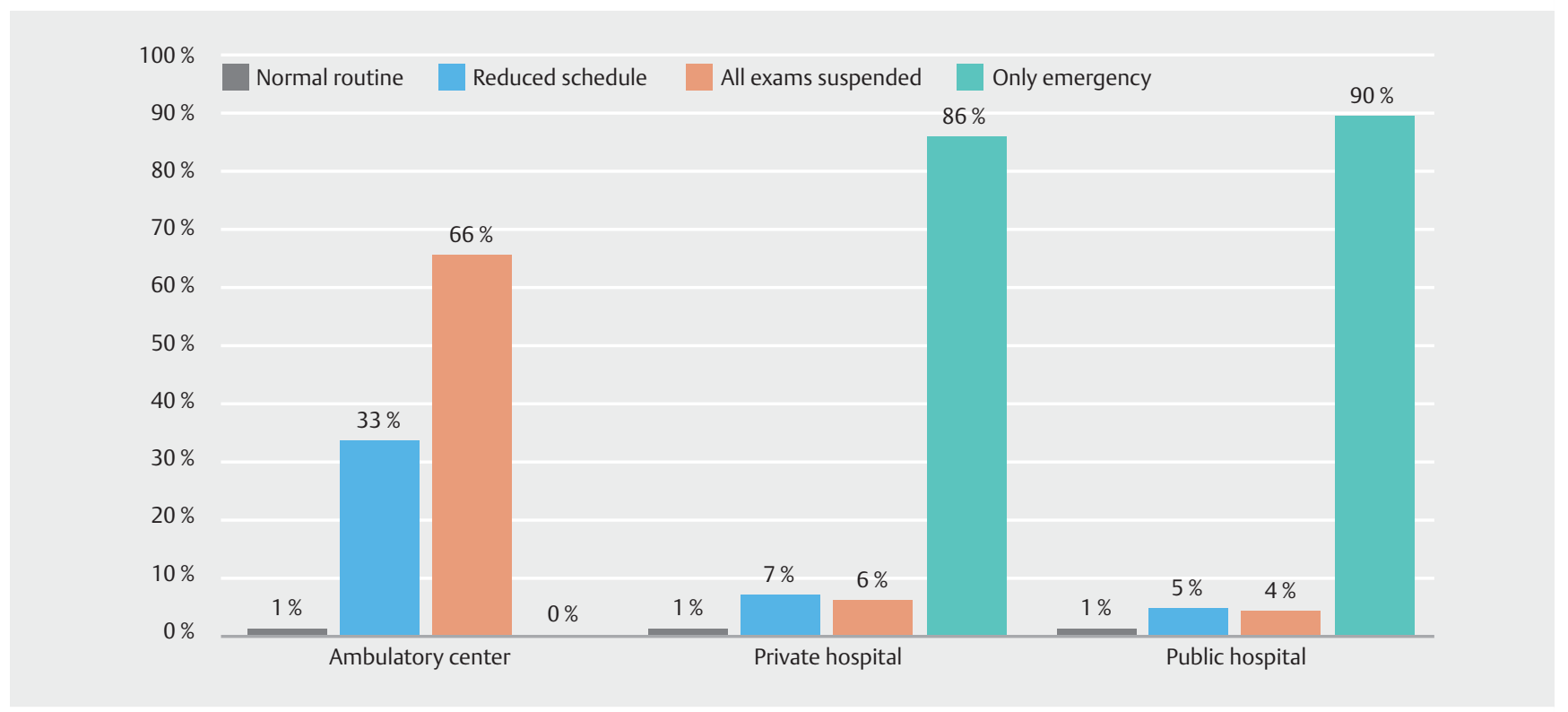

- Fig. 3 Impact on scheduling of routine endoscopy. 


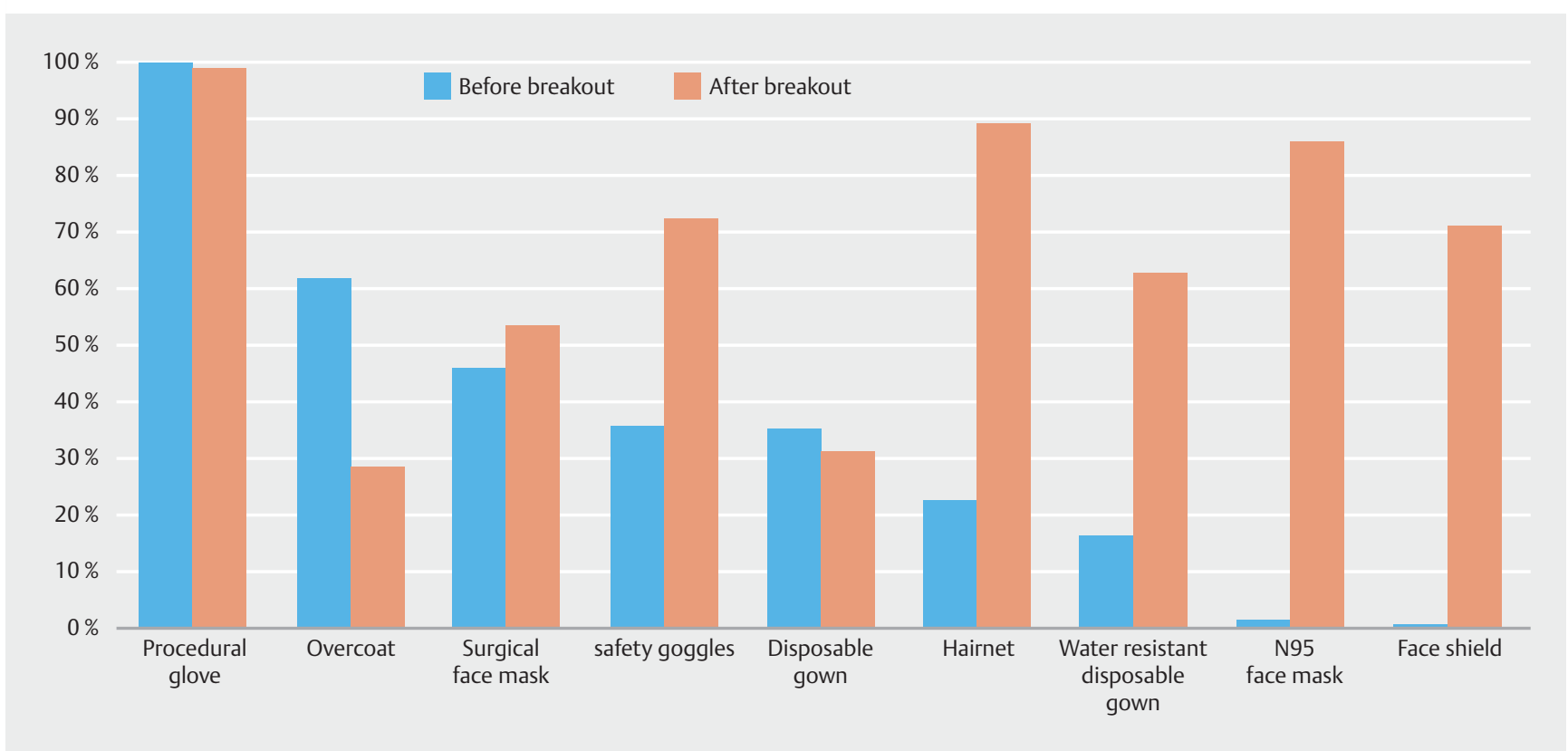

- Fig. 4 Personal protective equipment usage before and after the outbreak.

\section{Endoscopist exposure to COVID-19}

Ninety-nine participants (12.1\%) had to perform at least one endoscopic procedure on a patient diagnosed with COVID-19. The majority of the procedures were upper endoscopy and enteral tube placement. Sixty-nine participants (7.1\%) manifested COVID-19 symptoms but only 17 individuals (1.7\%) had serologic or swab confirmation of infection. Ten endoscopists ( $1 \%$ ) stated that the infection was secondary to endoscopic procedures performed in infected patients ( $\triangleright$ Table 2 ).

Only 57 practitioners $(8.3 \%$ ) were relocated to work in other hospital departments to assist COVID-19 patients due to lack of professionals to cover those areas. Concerning participants who remained at work and performing procedures, 647 individuals $(74.4 \%)$ continued living at home with their relatives, whereas 40 respondents ( $4.6 \%$ ) left their homes for another accommodation or hotel. Of note, 183 respondents (21\%) interrupted their labor activities completely.

\section{Financial impact}

A negative financial impact with income loss was universally experienced by almost all participants (99.9\%). The majority considered this income loss temporary and recoverable in the short term $(74.7 \%)$ or at least in the long term (12.2\%). Nonetheless, at this stage, $12.6 \%$ of the respondents considered the income loss extensive and irretrievable.

\section{Discussion}

This is probably the first and largest comprehensive report of the burden of the COVID-19 pandemic in the most affected country in Latin America, involving almost 1,000 endoscopists, which represents around one-third of our National Society (SOBED) associate members. It is important to highlight that only

\begin{tabular}{|c|c|c|}
\hline & $\mathbf{N}$ & $\%$ \\
\hline \multicolumn{3}{|c|}{ Performed endoscopy in COVID-19 patients? } \\
\hline - Yes & 99 & $12.1 \%$ \\
\hline - No & 707 & $86.5 \%$ \\
\hline - Refused & 11 & $1.4 \%$ \\
\hline \multicolumn{3}{|l|}{ Relocated to work in other department? } \\
\hline - Yes & 57 & $8.3 \%$ \\
\hline - No & 611 & $89.5 \%$ \\
\hline - Denied relocation & 15 & $2.2 \%$ \\
\hline \multicolumn{3}{|l|}{ Presented COVID-19 symptoms? } \\
\hline - No & 911 & $93 \%$ \\
\hline - Yes, but not confirmed with tests & 52 & $5.3 \%$ \\
\hline - Yes, confirmed by swab or serology & 17 & $1.7 \%$ \\
\hline
\end{tabular}

If COVID-19 confirmed, do you consider it was due to exposure during endoscopy?

\begin{tabular}{|l|r|r|}
\hline - No & 7 & $41.2 \%$ \\
\hline - Yes & 10 & $58.8 \%$ \\
\hline
\end{tabular}

qualified and complete responses were included. The current study reflects with high reliability the practice of endoscopy in Brazil during the COVID-19 pandemic.

At the time this survey was conducted, Brazil had an ascending curve of confirmed cases (from 20,000 to 40,000) and deaths, although it was less steep than in countries in the northern hemisphere. It is notable that $85 \%$ to $90 \%$ of endoscopy centers were affected by this crisis, with suspension or 
postponement of elective procedures, which led to the major economic impact experienced by almost all respondents. Twothirds of ambulatory endoscopy centers had completely interrupted endoscopic activities and the remaining one third had substantially decreased procedures workload.

Unfortunately, an important subset of Brazilian endoscopists faced a shortage or absence of essential PPE, resulting in either cancellation of procedures or performance of endoscopy under unsafe conditions. Moreover, it is extremely important to stress that endoscopy is considered an aerosol-generating procedure and a hazardous activity in times of coronavirus outbreak, and all efforts should be made by institutions and authorities to provide full PPE to practitioners on the frontline who are managing infected patients. Although the virus has only arrived in Brazil 5 weeks before this survey began, almost 100 endoscopists had already performed interventions in patients infected with COVID-19. Furthermore, it is of concern that 17 participants $(1.7 \%)$ were already contaminated with this infection, and 10 individuals ( $1 \%$ ) attributed their infection to exposure during endoscopy practice.

Right after the arrival of SARS-Cov2 in Brazil, SOBED created a taskforce to analyze the crisis in our country and to propose guidelines that could serve as orientation to the pandemic for all Brazilian endoscopy providers. Over a 1-week period (March 15 to March 21), SOBED published three position statements [16]. Based on the Italian experience [14], the first report suggested triage of low-/high-risk patients based on symptoms, contact with positive cases or visits to high-risk areas. However, community transmission was rapid in Brazil, and the Ministry of Health increased our status alert to high risk for the entire country. As a consequence, social distancing and suspension of commercial activities were implemented in an earlier phase of the outbreak, and only 1 week after the first statement, SOBED updated the guidelines and suggested suspension of elective endoscopy procedures [16]. This survey showed a high adherence rate of Brazilian endoscopists to this recommendation, in private and public hospitals and ambulatory centers, the latter basically performing only urgent exams. Distribution of the pandemic in Brazil was heterogeneous, with some regions responding that they had fewer than $10 \%$ of the cases [17]. Currently the debate is about what conditions are necessary to resume elective medical activities, at least in areas where the outbreak is not so severe.

Recently, another survey has been reported by Repici et al [18], conducted in high-risk areas of northern Italy. The coordinators of 41 endoscopic centers responded to the survey but individual endoscopists did not. The authors reported that most routine procedures had been cancelled or postponed, with most endoscopy units reporting a procedure reduction of more than $75 \%$. However, even in the epicenter of the COVID19 outbreak in Italy, screening colonoscopy for colorectal cancer in patients with positive fecal occult blood test was still being performed in 28 endoscopy units (68.3\%), outpatient therapeutic procedures in nine endoscopy units (22.0\%), and seven endoscopy units (17.1\%) maintained an uninterrupted workload for all endoscopy procedures. Considering the substantial differences in pandemic impact between Italy and Bra- zil, the restrictions adopted in Brazil may have been even more rigorous than in Italy.

There is a broad consensus regarding the policy for postponing elective endoscopic exams and it has been advocated by several endoscopy societies and health authorities [8-15]. Our survey also showed a high acceptance rate for these restrictive measures among both clinicians and patients. Such a strategy is important to protect patients and health care providers and to minimize risk of cross infection. In addition, it facilitates rational use of PPE and safety and maintenance of endoscopic teams. In contrast, a matter of debate that will challenge most endoscopy providers soon is how to reschedule postponed exams and what criteria to adopt to prioritize patients already on a waiting list and bring them in for procedures after the pandemic crisis has subsided [17]. The need for such a restrictive policy has been universally embraced, however, the impact on diagnostic delay with attendant negative consequences in management, at this stage, is still difficult to measure precisely.

A positive effect on daily practice of endoscopy in times of COVID-19 has been increased awareness and compliance of endoscopy providers about protective measures and PPE usage. Before the crisis, low adherence of health care providers to PPE use in endoscopy units was universal. Besides gloves, the most used PPE before the pandemic were surgical masks and personal tissue gowns, followed by goggles and disposable gown. After the coronavirus outbreak, use of PPE increased dramatically ( Fig.4), for example, hairnet usage increased from $22.6 \%$ to $89 \%$, goggles from $35.6 \%$ to $72.3 \%$, face shield from $0.6 \%$ to $70.9 \%$, N95 respirators from $1.4 \%$ to $85.9 \%$, and waterresistant gowns from $16.2 \%$ to $62.9 \%$. However, it is noteworthy that a significant number of Brazilian endoscopists were still challenged to work without proper PPE in their workplaces. As a result, almost $40 \%$ of endoscopists took the initiative to purchase their own PPE.

In relation to correct PPE donning and doffing, $69.9 \%$ of endoscopists referred to having learned these measures from Internet videos and other online publications, and $40 \%$ adopted their local Institution's protocol. This information underscores the importance of International Society actions and social networks. Colleagues all over the globe shared information regarding virus transmission and how to protect HCP and the patients against it. As a consequence of the massive adoption of PPE and restrictive activities, the current survey showed that a small number of endoscopists were infected allegedly due to endoscopic activity ( $1 \%$ of the total responses). By early March, approximately $20 \%$ of health care providers in Italy had been infected by SARS-Cov-2 [19]. In a survey conducted by Repici et al [18], 12 endoscopy units confirmed infections among nurses and physicians with six of them requiring hospitalization. However, there was no clear evidence of transmission directly related to endoscopic procedures in COVID-19-positive patients. Furthermore, it is important to emphasize that no nosocomial outbreaks due to endoscopic procedures were reported and no cases of endoscope-related COVID-19 infection have been reported so far, indicating that current endoscope disinfection techniques are adequate [20]. 
Availability of negative-pressure rooms for endoscopic procedures has been an issue in many hospitals, and that may be reflected in this survey, because only $13.2 \%$ of respondents reported having access to that kind of facility. The Italian survey [18] showed that seven endoscopy units (17.1\%) have negative-pressure rooms. Our Society guidelines [16], taking into consideration the absolute shortage of negative-pressure rooms all over the country, has determined that lack of a negative-pressure room should not be a contraindication to an endoscopy procedure in a patient with COVID-19, particularly if the indication is urgent.

Regarding relocation of professionals, so far as the COVID19 outbreak still has not reached a level of high stress on our health care system, very few endoscopists (8\%) have been asked to work in other hospital departments, particularly in frontline management of infected patients. In contrast in Italy, where the outbreak was much more severe that in Brazil so far, a total of 27 endoscopy units (65.9\%) relocated endoscopists to other hospital departments to provide clinical assistance for care of patients with COVID.

Brazilian endoscopists recognized that the COVID-19 pandemic brought substantial financial losses but most of them believe that this situation will be reversible in the short or long term. That fact probably reflects that, at this point, most Brazilian endoscopists have the common belief that endoscopy units will soon resume their agendas at full capacity. They probably do not foresee the need to increase the intervals between procedures, increase costs (with PPE), or triage both patients and health care providers for COVID-19 infection, just to mention some of the challenges that managers and physicians from endoscopy units will probably face in the near future, and most likely will result in income loss to all practitioners.

This study has some limitations, including the fact that it was based on endoscopists' personal reports and assuming they have provided reliable information. Furthermore, we have not checked the clinical condition of the physicians who reported COVID-19 contamination, nor could we trace the infection route to prove that the infection was acquired in the endoscopy unit. Likewise, this research did not investigate contamination of other endoscopic personnel such as nurses, residents or anesthesiologists. In addition, the true incidence of contaminated practitioners may have been underestimated in this survey, considering the possibility of underreporting of asymptomatic endoscopists exposed to the new coronavirus. Another concern is that an unknown number of endoscopists in Brazil were not reached by this survey, due to the fact that they are not current SOBED members. On the other hand, considering the dynamic pathway of the COVID-19 pandemic and the speed of events and growth of knowledge, the greatest strength of this study is that it is the largest portrait of COVID-19 pandemic burden on endoscopy practice in the largest country in Latin America, involving almost 1,000 practitioners with qualified responses, accurately reflecting the current impact of COVID-19 on endoscopy practice throughout the country.

\section{Conclusions}

In conclusion, based on this nationwide survey with almost 1,000 respondents, the COVID-19 pandemic significantly reduced the activity of endoscopy units located in private and public hospitals, and ambulatory centers. The pandemic increased endoscopist awareness of use of PPE. Unfortunately, the access PPE for endoscopic procedures was not universal. Medical societies and social media had a major role in training of health care personnel on how to done and doff PPE. Fortunately, only a minority of endoscopists (1\%) became infected with Sars-CoV-2.

\section{Acknowledgements}

The authors thank the associate members of SOBED for their participation in the survey. In addition, they thank Mrs. Silvia Sanches and Mrs. Gisele Cardoso of the SOBED administrative office for their contribution to the technical preparation and release of the online survey.

\section{Competing interests}

Fauze Maluf-Filho - consultant for Boston Scientific, Cook and Olympus. The other authors declare that there is no conflict of interest regarding the publication of this paper.

\section{References}

[1] Li Q, Guan X, Wu P et al. Early transmission dynamics in Wuhan, China, of Novel coronavirus-infected pneumonia. N Engl J Med 2020; 382: 1199-207

[2] WHO Director-General's opening remarks at the media briefing on COVID-19 - 11 March 2020. https://www.who.int/dg/speeches/detail/who-director-general-s-opening-remarks-at-the-media-briefingon-covid-19

[3] Ye F, Xu S, Rong Z et al. Delivery of infection from asymptomatic carriers of COVID-19 in a familial cluster. Int J Infect Dis 2020; 94: 133138

[4] Li C, Ji F, Wang L et al. Asymptomatic and human-to-human transmission of SARS-CoV-2 in a 2-family cluster, Xuzhou, China. Emerg Infect Dis 2020; 26: doi:10.3201/eid2607.200718

[5] Li R, Pei S, Chen B et al. Substantial undocumented infection facilitates the rapid dissemination of novel coronavirus (SARS-CoV2). Science 2020; 368: 489-493

[6] Chan JFW, Yuan S, Kok KH et al. A familial cluster of pneumonia associated with the 2019 novel coronavirus indicating person-to-person transmission: a study of a family cluster. Lancet 2020; 395: 514-523

[7] World Endoscopy Organization. WEO recommendations on digestive endoscopy and the COVID-19 pandemic | World Endoscopy Organization (WEO). Im Internet (cited 2020 Apr 22): http://www.worldendo.org/2020/03/24/weo-advice-on-digestive-endoscopy-and-thecovid-19-pandemic/

[8] Sociedade Brasileira de Endoscopia Digestiva (SOBED). Recomendações SOBED para Endoscopia Segura durante a pandemia por Coronavirus - Sobed.https://www.sobed.org.br/sobed-comunica/noticias/ single/nid/recomendacoes-sobed-para-endoscopia-segura-durantea-pandemia-por-coronavirus/ 
[9] Lui RN, Wong SH, Sánchez-Luna SA et al. Overview of guidance for endoscopy during the coronavirus disease 2019 (COVID-19) pandemic. J Gastroenterol Hepatol 2020; 35: 749-759

[10] Joint GI Society. Message on COVID-19 - American College of Gastroenterology.https://gi.org/2020/03/15/joint-gi-society-message-oncovid-19/

[11] Considerations for Australian endoscopy units during the COVID-19 pandemic. https://www.gesa.org.au/resources/covid-19

[12] Gralnek IM, Hassan C, Beilenhoff $U$ et al. ESGE and ESGENA Position Statement on gastrointestinal endoscopy and the COVID-19 pandemic. Endoscopy 2020: doi:10.1055/a-1155-6229

[13] The British Society of Gastroenterology. Endoscopy activity and COVID-19: BSG and JAG guidance - update 03.04.20. https://www.bsg. org.uk/covid-19-advice/endoscopy-activity-and-covid-19-bsg-andjag-guidance

[14] Repici A, Maselli R, Colombo M et al. Coronavirus (COVID-19) outbreak: what the department of endoscopy should know. Gastrointest Endosc 2020: doi:10.1016/j.gie.2020.03.019
[15] Agencia Nacional de Vigilancia Sanitaria (ANVISA). NOTA TÉCNICA No 04/2020 GVIMS/GGTES/ANVISA - ATUALIZADA EM 21/03/2020. https://www20.anvisa.gov.br/segurancadopaciente/index.php/alertas/item/nota-tecnica-n-04-2020-gvims-ggtes-anvisa-atualizadaem-21-03-2020? category_id=244

[16] Sociedade Brasileira de Endoscopia Digestiva (SOBED). Noticias covid19 - Sobed.https://www.sobed.org.br/sobed-comunica/noticiascovid19/

[17] Ponchon T, Chaussade S. COVID-19: How to select patients for endoscopy and how to reschedule the procedures? Endosc Int Open 2020; 08: E699-E700

[18] Repici A, Pace F, Gabbiadini R et al. Endoscopy units and the COVID-19 outbreak: a multi-center experience from Italy. Gastroenterology 2020: doi:10.1053/j.gastro.2020.04.003

[19] Remuzzi A, Remuzzi G. COVID-19 and Italy: what next? Lancet 2020; 395: $1225-1228$

[20] Perisetti A, Gajendran M, Boregowda U et al. COVID-19 and gastrointestinal endoscopies: current insights and emergent strategies. Dig Endosc 2020: doi:10.1111/den.13693 